\title{
Article \\ Association of Mean and Variability of HbA1c with Heart Failure in Patients with Type 2 Diabetes
}

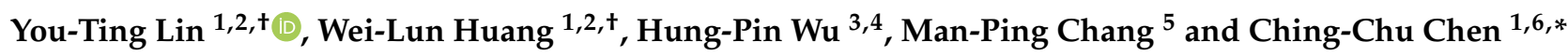 \\ 1 Division of Endocrinology and Metabolism, Department of Medicine, China Medical University Hospital, \\ Taichung 40447, Taiwan; linsx221@gmail.com (Y.-T.L.); d4312@mail.cmuh.org.tw (W.-L.H.) \\ 2 Department of Medicine, China Medical University, Taichung 40402, Taiwan \\ 3 Division of Cardiovascular Medicine, Department of Medicine, China Medical University Hospital, \\ Taichung 40447, Taiwan; shuwpingwu@gmail.com \\ 4 School of Medicine, China Medical University, Taichung 40402, Taiwan \\ 5 Department of Nursing, National Taichung University of Science and Technology, Taichung 40354, Taiwan; \\ manping725@gmail.com \\ 6 School of Chinese Medicine, China Medical University, Taichung 40402, Taiwan \\ * Correspondence: chingchu@ms15.hinet.net; Tel.: +886-4-2206-2121 (ext. 4676) \\ + These authors contributed equally to this work.
}

\section{check for}

updates

Citation: Lin, Y.-T.; Huang, W.-L.; Wu, H.-P.; Chang, M.-P.; Chen, C.-C. Association of Mean and Variability of $\mathrm{HbA} 1 \mathrm{c}$ with Heart Failure in

Patients with Type 2 Diabetes. J. Clin. Med. 2021, 10, 1401. https://doi.org/ $10.3390 /$ jcm10071401

Received: 18 February 2021

Accepted: 26 March 2021

Published: 1 April 2021

Publisher's Note: MDPI stays neutral with regard to jurisdictional claims in published maps and institutional affiliations.

Copyright: (c) 2021 by the authors. Licensee MDPI, Basel, Switzerland. This article is an open access article distributed under the terms and conditions of the Creative Commons Attribution (CC BY) license (https:// creativecommons.org/licenses/by/ $4.0 /)$.

\begin{abstract}
Heart failure (HF) is a common presentation in patients with type 2 diabetes mellitus (T2DM). Previous studies revealed that the HbA1c level is significantly associated with HF. However, little is known about the association between $\mathrm{HbA} 1 \mathrm{c}$ variability and HF. We aimed to evaluate the association of mean and variability of $\mathrm{HbA} 1 \mathrm{c}$ with $\mathrm{HF}$ in patients with T2DM. Using Diabetes Share Care Program data, patients with T2DM who had mean HbA1c (HbA1c-Mean), and HbA1c variability (tertiles of $\mathrm{HbA1c-SD}$ and $\mathrm{HbA1c}$-adjSD) within 12-24 months during 2001-2008 were included. The cutoffs of HbA1c-Mean were set at $<7 \%, 7-7.9 \%$, and $\geq 8 \%$. Hazard ratios (HRs) for HF during 2008-2018 were estimated using Cox proportional hazard models. A total of 3824 patients were included, of whom 315 patients developed HF during the observation period of 11.72 years. The associated risk of HF increased with tertiles of $\mathrm{HbA} 1 \mathrm{c}$ variability and cutoffs of $\mathrm{HbA1c}-\mathrm{Mean}$. In mutually adjusted models, HbA1c-Mean showed a consistent dose-response association with HF, while the association of $\mathrm{HbA1c}$ variability with $\mathrm{HF}$ disappeared. Among patients with $\mathrm{HbA1c}-\mathrm{Mean}$ $<7 \%$, the associated risk of $\mathrm{HF}$ in patients with $\mathrm{HbA} 1 \mathrm{c}$ variability in tertile 3 was comparable to patients with $\mathrm{HbA} 1 \mathrm{c}-\mathrm{Mean} \geq 8 \%$. In conclusion, mean $\mathrm{HbA} 1 \mathrm{c}$ was an independent predictor of $\mathrm{HF}$ and not explained by $\mathrm{HbA1c}$ variability. In addition to absolute $\mathrm{HbA1c}$ level, targeting on stability of $\mathrm{HbA1c}$ in patients with good glycemic control was also important for the development of HF in patients with T2DM.
\end{abstract}

Keywords: HbA1c; glycated hemoglobin; variability; heart failure; diabetes

\section{Introduction}

Heart failure (HF) is one of the most common initial manifestations of cardiovascular disease in patients with type 2 diabetes mellitus (T2DM) [1]. A previous study showed that the mortality rate of patients with diabetes and HF is 4- to 6-fold higher than patients with diabetes who do not develop HF [2]. A recent study also reported that the development of HF is associated with the highest five-year risk of death compared with the development of other cardiovascular diseases in patients newly diagnosed with T2DM [3]. An epidemiological study revealed that the incidence of HF is approximately two times higher in patients with diabetes than patients without diabetes [4]. Clinically, hypertension and coronary heart disease are well-known causes of HF. These two risk factors are common comorbidities in patients with T2DM [5], which may partly explain the higher incidence of HF in patients with diabetes. However, previous studies have shown that 
diabetes itself is an independent risk factor for the development of HF irrespective of blood pressure and coronary heart disease [6,7], which implies that there is a residual risk(s) for the development of HF in patients with T2DM. Several studies revealed that glycated hemoglobin $(\mathrm{HbA1c})$ level is positively associated with HF in patients with T2DM [8-12]. In addition, a cohort study reported that a $1 \%$ reduction in mean $\mathrm{HbA} 1 \mathrm{c}$ is associated with a $16 \%$ risk reduction in HF [13]. Recently, many studies have shown that HbA1c variability is positively associated with macrovascular complications [14-16] and all-cause mortality [17] in patients with T2DM. However, little is known about the association of $\mathrm{HbA} 1 \mathrm{c}$ variability with $\mathrm{HF}$. In this study, we aimed to examine the associated risk of HbA1c variability and mean $\mathrm{HbA} 1 \mathrm{c}$ with $\mathrm{HF}$ in patients with T2DM.

\section{Materials and Methods}

\subsection{Data Source and Design}

In 2001, the Taiwan National Health Insurance Bureau established a Diabetes Shared Care Program to promote diabetes care. In this program, certified diabetes educators used a standardized electronic questionnaire to record basic data, personal habits, current and past diseases, and medications. Patients with a clinical diagnosis of diabetes were enrolled in the program at the outpatient clinic of China Medical University hospital, Taichung, Taiwan. In this study, we used data of patients enrolled between January 2001 and April 2008 for study analyses. The exclusion criteria included patients with a history of HF before enrollment, development of HF within 1 year after enrollment (for avoiding reverse causality), aged $>80$ years, age of diabetes onset $<30$ years, type 1 DM, cardiac dysrhythmia, congenital heart disease, valvular heart disease, estimated glomerular filtration rate $(\mathrm{eGFR})<30 \mathrm{~mL} / \mathrm{min} / 1.73 \mathrm{~m}^{2}$, and $\mathrm{HbA} 1 \mathrm{c}$ measurements fewer than three times within 12-24 months. We linked each patient's personal identification number to the annual inpatient and outpatient claim database of the Taiwan National Health Insurance which uses the International Classification of Diseases, Ninth Revision, Clinical Modification (ICD-9-CM) or ICD-10-CM codes for diseases diagnosis, provided by the Taiwan Health and Welfare Data Science Center, to verify the diagnoses of primary outcome (HF) and cardiovascular risk factors (hypertension, coronary heart disease, valvular heart disease, congenital heart disease, cardiac dysrhythmia, and stroke). Each patient was followed from the identified date to the development of HF, death, or 31 December 2018. The ICD-9-CM and ICD-10-CM codes used in this study were presented in Supplementary Table S1. Because of the limitation of ICD-9-CM and ICD-10-CM codes, we do not have the New York Heart Association Functional Class for HF staging. This study was approved and granted a waiver of informed consent by the Ethical Review Board of China Medical University Hospital in Taiwan (CMUH107-REC2-163). All methods were carried out in accordance with the Declaration of Helsinki.

\subsection{Statistical Analyses}

The mean and standard deviation (SD) of continuous variables and number and percentage for categorical variables were used to describe the distributions of the patients. The Student's t test and the chi-square test (or the Fisher's exact test) were used to compare continuous and categorical variables between patients with $\mathrm{HF}$ and patients without $\mathrm{HF}$, respectively. $\mathrm{HbA1c}$ variability was presented with $\mathrm{SD}(\mathrm{HbA1c}-\mathrm{SD})$. Because the number of $\mathrm{HbA1c}$ measurements could influence the SD [18], the inter-individual difference in the numbers of $\mathrm{HbA} 1 \mathrm{c}$ measurements was adjusted according to the formula: $\mathrm{SD} / \sqrt{ }(\mathrm{n} /(\mathrm{n}-1))$ (HbA1c-adjSD) [18]. For comparison, individuals' HbA1c-SD and HbA1c-adjSD were divided by tertiles; for mean $\mathrm{HbA} 1 \mathrm{c}$ (HbA1c-Mean), the cutoffs were set at $<7 \%, 7-7.9 \%$, and $\geq 8 \%$. A Cox proportional hazard model was used to estimate the hazard ratios (HRs) and 95\% confidence intervals. Multiple confounders in the adjusted model included sex, age, diabetes duration, body mass index, systolic blood pressure, total cholesterol, triglyceride, high-density lipoprotein cholesterol, low-density lipoprotein cholesterol, eGFR, coronary heart disease, hypertension, stroke, the use of sulfonylureas, metformin, thiazolinediones, 
insulin, statin, antiplatelet agents, warfarin, angiotensin converting enzyme inhibitors, angiotensin II receptor blockers, beta-blockers, calcium channel blockers, diuretics, and alpha-blockers. In Table 2, model 1 was adjusted for multiple confounders; model 2 was a mutually (HbA1c-SD or HbA1c-adjSD vs. HbA1c-Mean) adjusted model. Namely, HbA1c variability (HbA1-SD or $\mathrm{HbA1c}$-adjSD) was adjusted for multiple confounders plus mean $\mathrm{HbA1c}$ (HbA1c-Mean). For Mean HbA1c (HbA1c-Mean), it was adjusted for multiple confounders plus $\mathrm{HbA1c}$ variability, either HbA1c-SD (shown with stars) or HbA1c-adjSD (shown with hashtags). Data management and analysis were performed using SAS 9.4 software (SAS Institute, Cary, NC, USA). The significance level was set at a $p$-value $<0.05$ for two-sided testing.

\section{Results}

As shown in Supplementary Figure S1, a total of 8636 patients were enrolled in the program. We excluded 285 patients with a history of HF before enrollment, 44 patients who developed HF within 12 months after enrollment, 195 patients with age at enrollment of $>80$ years, 516 patients with age at diabetes onset of $<30$ years, 170 patients with type $1 \mathrm{DM}, 246$ patients with cardiac dysrhythmia, 4 patients with congenital heart disease, 55 patients with valvular heart disease, 173 patients with eGFR $<30 \mathrm{~mL} / \mathrm{min} / 1.73 \mathrm{~m}^{2}$, and 3124 patients who underwent $\mathrm{HbA1c}$ measurement fewer than three times. In total, 3824 patients were identified for analyses in this study; among these, 315 patients developed HF during the observation period of 11.72 years.

As shown in Table 1, the patients who developed HF had older ages, diabetes for longer, higher systolic blood pressure and higher mean HbA1c, lower eGFR, more cardiovascular diseases, been administered more sulfonylureas, thiazolidinediones, insulin, statin and cardiovascular medications, and higher $\mathrm{HbA} 1 \mathrm{c}$ variability and a larger proportion of patients with $\mathrm{HbA} 1 \mathrm{c} \geq 8 \%$ at baseline than patients who did not develop HF.

Table 1. Baseline characteristics of the study patients.

\begin{tabular}{|c|c|c|c|}
\hline & Non-HF & HF & \\
\hline Variables & $(n=3509)$ & $(n=315)$ & $p$-Value \\
\hline Man & $1785(50.9 \%)$ & $134(42.5 \%)$ & 0.005 \\
\hline Age, years & $57.3(10.7)$ & $63.9(9.4)$ & $<0.001$ \\
\hline Diabetes duration, years & $6.1(6.5)$ & $10.1(7.3)$ & $<0.001$ \\
\hline Body mass index, $\mathrm{kg} / \mathrm{m}^{2}$ & $25.4(3.8)$ & $25.8(4.2)$ & 0.083 \\
\hline Systolic blood pressure, $\mathrm{mmHg}$ & $134.6(17.4)$ & $140.6(18.0)$ & $<0.001$ \\
\hline Fasting plasma glucose, $\mathrm{mg} / \mathrm{dL}$ & $162.7(58.9)$ & $170.6(66.7)$ & 0.043 \\
\hline Mean $\mathrm{HbA} 1 \mathrm{c}$ & $7.7(1.3)$ & $8.2(1.6)$ & $<0.001$ \\
\hline Total Cholesterol & $195.5(43.2)$ & $201.5(45.1)$ & 0.018 \\
\hline Triglyceride & $160.3(194.0)$ & $177.2(120.1)$ & 0.025 \\
\hline HDL-cholesterol, mg/dL & $41.3(11.5)$ & $39.7(9.5)$ & 0.004 \\
\hline LDL-cholesterol, mg/dL & $120.0(35.6)$ & $121.7(37.1)$ & 0.422 \\
\hline Creatinine, $\mathrm{mg} / \mathrm{dL}$ & $0.9(0.3)$ & $1.0(0.3)$ & $<0.001$ \\
\hline $\mathrm{eGFR}, \mathrm{mL} / \mathrm{min} / 1.73 \mathrm{~m}^{2}$ & & & $<0.001$ \\
\hline $30-59$ & $451(12.9 \%)$ & $105(33.3 \%)$ & \\
\hline$\geq 60$ & $3058(87.1 \%)$ & $210(66.7 \%)$ & \\
\hline mean & $87.3(24.6)$ & $72.7(24.7)$ & $<0.001$ \\
\hline Exercise & $1676(59.1 \%)$ & $142(58.9 \%)$ & 0.952 \\
\hline Smoking & $636(18.1 \%)$ & $41(13.0 \%)$ & 0.023 \\
\hline Alcohol-drinking & $417(11.9 \%)$ & $24(7.6 \%)$ & 0.024 \\
\hline Coronary heart disease & $361(10.3 \%)$ & $70(22.2 \%)$ & $<0.001$ \\
\hline Hypertension & $1636(46.6 \%)$ & $219(69.5 \%)$ & $<0.001$ \\
\hline Stroke & $409(11.7 \%)$ & $73(23.2 \%)$ & $<0.001$ \\
\hline \multicolumn{4}{|l|}{ Medications } \\
\hline sulfonylureas & $2805(79.9 \%)$ & $267(84.8 \%)$ & 0.039 \\
\hline metformin & $1255(35.8 \%)$ & $108(34.3 \%)$ & 0.599 \\
\hline thiazolidinediones & $727(20.7 \%)$ & $90(28.6 \%)$ & 0.001 \\
\hline insulin & $727(20.7 \%)$ & $90(28.6 \%)$ & 0.001 \\
\hline
\end{tabular}


Table 1. Cont.

\begin{tabular}{|c|c|c|c|}
\hline & Non-HF & HF & \\
\hline Variables & $(n=3509)$ & $(n=315)$ & $p$-Value \\
\hline statin & $739(21.1 \%)$ & $91(28.9 \%)$ & 0.001 \\
\hline antiplatelet agents & $317(9.0 \%)$ & $65(20.6 \%)$ & $<0.001$ \\
\hline warfarin & $14(0.4 \%)$ & $6(1.9 \%)$ & 0.004 \\
\hline angiotensin converting enzyme inhibitors & $1107(31.5 \%)$ & $151(47.9 \%)$ & $<0.001$ \\
\hline angiotensin II receptor blockers & $640(18.2 \%)$ & $106(33.7 \%)$ & $<0.001$ \\
\hline HbA1c-SD & & & 0.011 \\
\hline tertile1 & $1215(34.6 \%)$ & $84(26.7 \%)$ & \\
\hline tertile2 & $1138(32.4 \%)$ & $122(38.7 \%)$ & \\
\hline tertile3 & $1156(32.9 \%)$ & $109(34.6 \%)$ & \\
\hline $\mathrm{HbA1c}-\mathrm{adjSD}$ & & & 0.037 \\
\hline tertile1 & $1181(33.7 \%)$ & $84(26.7 \%)$ & \\
\hline tertile2 & $1174(33.5 \%)$ & $120(38.1 \%)$ & \\
\hline tertile3 & $1154(32.9 \%)$ & $111(35.2 \%)$ & \\
\hline HbA1c-Mean & & & $<0.001$ \\
\hline$<7 \%$ & $1098(31.3 \%)$ & $70(22.2 \%)$ & \\
\hline $7-7.9 \%$ & $1216(34.7 \%)$ & $97(30.8 \%)$ & \\
\hline$\geq 8 \%$ & $1195(34.1 \%)$ & $148(47.0 \%)$ & \\
\hline
\end{tabular}

HF, heart failure; SD, standard deviation; eGFR, estimated glomerular filtration rate; HDL, High-density lipoprotein; LDL: Lowdensity lipoprotein.

Table 2 reveals that the crude risk of HF increased with tertiles of $\mathrm{HbA1c}-\mathrm{SD}$ (tertile 2 vs. tertile 1, HR 1.53 [1.16-2.02], $p=0.002$; tertile 3 vs. tertile 1, HR 1.38 [1.04-1.83], $p=0.026$ ), HbA1c-adjSD (tertile 2 vs. tertile 1, HR 1.43 [1.08-1.89], $p=0.012$; tertile 3 vs. tertile 1, HR 1.37 [1.03-1.82], $p=0.029$ ) and higher HbA1c-Mean (mean HbA1c $\geq 8 \%$ vs. $<7 \%$, HR 1.85 [1.39-2.46], $p<0.001$ ). After adjustment for multiple confounders (shown in model 1), the associations of HbA1c-SD (tertile 2 vs. tertile 1, HR 1.39 [1.04-1.85], $p=0.024$; tertile 3 vs. tertile 1, HR 1.42 [1.04-1.92], $p=0.025$ ), HbA1c-adjSD (tertile 3 vs. tertile 1, HR 1.39 [1.03-1.88], $p=0.032$ ), and HbA1c-Mean (mean HbA1c $\geq 8 \%$ vs. $<7 \%$, HR 1.66 [1.20-2.29], $p=0.002$ ) remained. In model 2 (a mutually adjusted model), after further adjustment for $\mathrm{HbA1c}-M e a n$, the associated risk of $\mathrm{HbA1c}-\mathrm{SD}$ (tertile 2 vs. tertile 1, HR 1.29 [0.96-1.73], $p=0.095$; tertile 3 vs. tertile 1 , HR 1.17 [0.84-1.64], $p=0.350$ ), and HbA1cadjSD (tertile 2 vs. tertile 1, HR 1.19 [0.89-1.60], $p=0.239$; tertile 3 vs. tertile 1 , HR 1.16 [0.83-1.61], $p=0.386$ ) with HF disappeared. However, the associated risk of HbA1c-Mean with HF remained an even further adjustment for either HbA1c-SD (shown with stars) (HbA1c-Mean $\geq 8 \%$ vs. $<7 \%$, HR 1.56 [1.09-2.22], $p=0.015$ ), or HbA1c-adjSD (shown with hashtags) (mean HbA1c $\geq 8 \%$ vs. $<7 \%$, HR 1.57 [1.10-2.23], $p=0.013$ ).

Supplementary Table S2 shows all HRs by categories of tertiles of HbA1c-SD or HbA1cadjSD and cutoffs of HbA1c-Mean. As shown in Figure 1A, the crude HR reveals that the risk of HF was lowest in patients with $\mathrm{HbA1c}$-adjSD in tertile 1 and $\mathrm{HbA1c}-\mathrm{Mean}<7 \%$; highest in those patients with $\mathrm{HbA1c}$-adjSD in tertile 1 and $\mathrm{HbA1c}-M e a n \geq 8 \%$, followed by $\mathrm{HbA1c}$-adjSD in tertile 3 and $\mathrm{HbA1c}-M e a n \geq 8 \%$, then by HbA1c-adjSD in tertile 3 and $\mathrm{HbA1c}-$ Mean $<7 \%$. When adjusting for multiple confounders (Figure 1B), the HF risk of patients with $\mathrm{HbA1c}-$ Mean $<7 \%$ and HbA1c-adjSD in tertile 3 was comparable with those patients with $\mathrm{HbA1c}-\mathrm{Mean} \geq 8 \%$ and HbA1c-adjSD in either tertile 1 or tertile 3 . 
Table 2. Hazard ratios of heart failure by measures of HbA1c variability and mean HbA1c.

\begin{tabular}{|c|c|c|c|c|c|c|}
\hline \multirow[b]{3}{*}{ Variable } & \multirow[b]{2}{*}{ Crude } & \multirow[b]{3}{*}{$p$-Value } & \multicolumn{4}{|c|}{ Adjusted } \\
\hline & & & \multirow{2}{*}{$\begin{array}{c}\text { Model } 1 \\
\text { HR [95\%CI] }\end{array}$} & \multicolumn{3}{|c|}{ Model 2} \\
\hline & HR [95\%CI] & & & $p$-Value & HR $[95 \% C I]$ & $p$-Value \\
\hline tertile 1 & 1.00 [ref.] & & 1.00 [ref.] & & 1.00 [ref.] & \\
\hline tertile 2 & 1.53 [1.16-2.02] & 0.002 & 1.39 [1.04-1.85] & 0.024 & $1.29[0.96-1.73]$ & 0.095 \\
\hline tertile 3 & 1.38 [1.04-1.83] & 0.026 & 1.42 [1.04-1.92] & 0.025 & 1.17 [0.84-1.64] & 0.350 \\
\hline \multicolumn{7}{|c|}{ HbA1c-adjSD } \\
\hline tertile 1 & 1.00 [ref.] & & 1.00 [ref.] & & 1.00 [ref.] & \\
\hline tertile 2 & 1.43 [1.08-1.89] & 0.012 & 1.29 [0.97-1.72] & 0.086 & 1.19 [0.89-1.60] & 0.239 \\
\hline tertile 3 & 1.37 [1.03-1.82] & 0.029 & 1.39 [1.03-1.88] & 0.032 & $1.16[0.83-1.61]$ & 0.386 \\
\hline \multicolumn{7}{|c|}{ HbA1c-Mean } \\
\hline$<7 \%$ & 1.00 [ref.] & & 1.00 [ref.] & & $\star 1.00$ [ref.] & \\
\hline $7-7.9 \%$ & $1.22[0.90-1.66]$ & 0.204 & 1.20 [0.88-1.65] & 0.259 & $\star 1.15$ [0.83-1.58] & 0.411 \\
\hline$\geq 8 \%$ & 1.85 [1.39-2.46] & $<0.001$ & 1.66 [1.20-2.29] & 0.002 & $\star 1.56$ [1.09-2.22] & 0.015 \\
\hline \multicolumn{7}{|c|}{ HbA-1c-Mean } \\
\hline$<7 \%$ & 1.00 [ref.] & & 1.00 [ref.] & & \# 1.00 [ref.] & \\
\hline $7-7.9 \%$ & $1.22[0.90-1.66]$ & 0.204 & $1.20[0.88-1.65]$ & 0.259 & \# 1.16 [0.84-1.59] & 0.376 \\
\hline$\geq 8 \%$ & 1.85 [1.39-2.46] & $<0.001$ & 1.66 [1.20-2.29] & 0.002 & \# 1.57 [1.10-2.23] & 0.013 \\
\hline
\end{tabular}

HR, hazard ratio. Model 1: adjusted for multiple confounders (shown in method). Model 2 was a mutually adjusted model. Namely, $\mathrm{HbA1c}$ variability (HbA1-SD or HbA1c-adjSD) was adjusted for multiple confounders plus mean HbA1c (HbA1c-Mean). For Mean HbA1c (HbA1c-Mean), it was adjusted for multiple confounders plus HbA1c variability, either HbA1c-SD (shown with stars ${ }^{\star}$ ) or HbA1c-adjSD (shown with hashtags \#). Multiple cofounders were shown in the method.
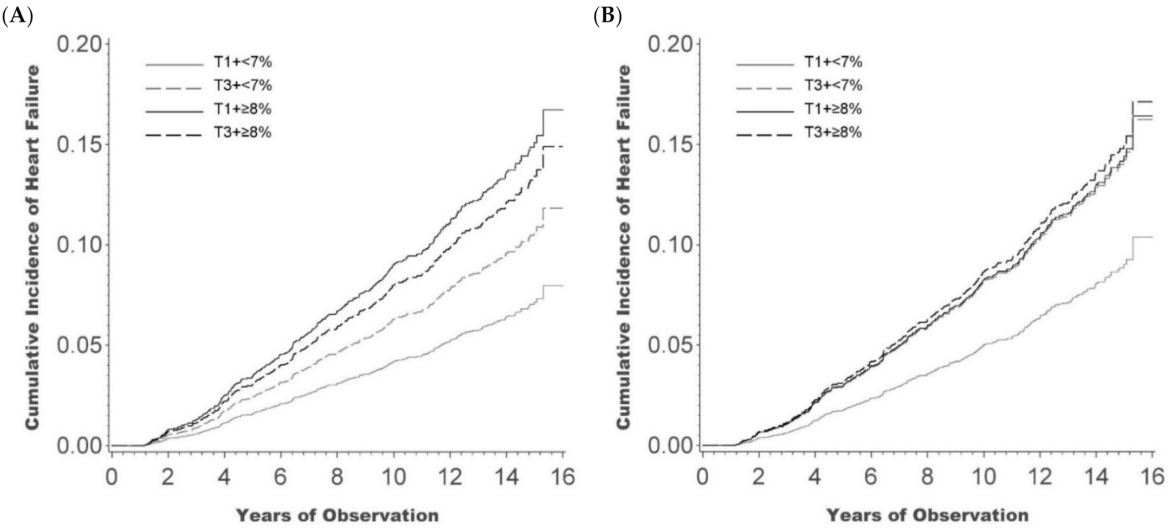

Figure 1. The hazard ratios (HRs) of heart failure (HF) by categories of HbA1c-adjSD and HbA1cMean. (A) The crude HRs reveals that the risk of HF was lowest in patients with HbA1c-adjSD in tertile 1 and $\mathrm{HbA1c}-$ Mean $<7 \%$; highest in those patients with HbA1c-adjSD in tertile 1 and HbA1cMean $\geq 8 \%$, followed by HbA1c-adjSD in tertile 3 and HbA1c-Mean $\geq 8 \%$, then by HbA1c-adjSD in tertile 3 and $\mathrm{HbA} 1 \mathrm{c}-$ Mean $<7 \%$. (B) When adjusting for multiple confounders, the HF risk of patients with $\mathrm{HbA1c}-\mathrm{Mean}<7 \%$ and $\mathrm{HbA1c}$-adjSD in tertile 3 was comparable with those patients with $\mathrm{HbA} 1 \mathrm{c}-\mathrm{Mean} \geq 8 \%$ and $\mathrm{HbA1c}$-adjSD in either tertile 1 or tertile 3 . Abbreviation: T, tertile.

\section{Discussion}

This study shows that a raised mean HbA1c level is associated with a higher risk of developing HF. The effect of $\mathrm{HbA1c}$ variability on $\mathrm{HF}$ was crucial in patients with mean $\mathrm{HbA} 1 \mathrm{c}<7 \%$. The associated risk of $\mathrm{HF}$ in patients with mean $\mathrm{HbA} 1 \mathrm{c}<7 \%$ and greater $\mathrm{HbA} 1 \mathrm{c}$ variability was comparable to patients with $\mathrm{HbA} 1 \mathrm{c} \geq 8 \%$, irrespective of HbA1c variability.

The reported associated risk of mean $\mathrm{HbA1c}$ with $\mathrm{HF}$ or $\mathrm{HbA} 1 \mathrm{c}$ variability with $\mathrm{HF}$ has been summarized in Table 3. Many previous studies revealed that HbA1c level is positively associated with HF in patients with T2DM [8-12]. However, these studies did not take $\mathrm{HbA} 1 \mathrm{c}$ variability into consideration for the adjustment. So far, there have been 
few studies evaluating the association of $\mathrm{HbA} 1 \mathrm{c}$ variability with $\mathrm{HF}$. A longitudinal study with small patient numbers (201 subjects) and limited HF events (18 events) showed a positive association between $\mathrm{HbA1c}$ variability and new-onset HF [19]. Another study focused on the prediction of incident $\mathrm{HF}$ by mean $\mathrm{HbA} 1 \mathrm{c}$, and additionally reported that less $\mathrm{HbA1c}$ variability has a lower incidence of HF [20]. Again, this study [20] did not adjust for mean $\mathrm{HbA} 1 \mathrm{c}$ in the analyses of the association between $\mathrm{HbA} 1 \mathrm{c}$ variability and HF. Recently, a secondary analysis of the Action to Control Cardiovascular Risk in Diabetes trial reported an independent association between $\mathrm{HbA} 1 \mathrm{c}$ variability and $\mathrm{HF}$ risk [21]. This report also did not include mean $\mathrm{HbA1c}$ in the adjustment model. In our study, the multiple confounders-adjusted model (model 1) showed that HbA1c variability, HbA1c-SD (tertile 2 vs. tertile 1, HR 1.53 [1.16-2.02], $p=0.002$; tertile 3 vs. tertile 1 , HR 1.38 [1.04-1.83], $p=0.026$ ) and mean HbA1c level, mean $\mathrm{HbA} 1 \mathrm{c} \geq 8 \%$ vs. $<7 \%$, HR 1.85 [1.39-2.46], $p<0.001$, independently predicted HF. In mutually adjusted models (model 2), however, only mean $\mathrm{HbA} 1 \mathrm{c}$ revealed a consistent dose-response association, for example, after further adjustment for $\mathrm{HbA1c}-\mathrm{SD}, \mathrm{HbA} 1 \mathrm{c}-M e a n \geq 8 \%$ vs. $<7 \%$, HR 1.56 [1.09-2.22], $p=0.015$, while the association of HbA1c variability with HF disappeared, for example, after further adjustment for HbA1c-Mean, HbA1c-SD (tertile 2 vs. tertile 1, HR 1.29 [0.96-1.73], $p=0.095$; tertile 3 vs. tertile 1, HR 1.17 [0.84-1.64], $p=0.350$, which indicated that the association of $\mathrm{HbA1c}$ variability was largely explained by mean $\mathrm{HbA1c}$. Nevertheless, $\mathrm{HbA} 1 \mathrm{c}$ variability is still important among patients with good glycemic control. The risk of HF in good glycemic control patients with greater $\mathrm{HbA} 1 \mathrm{c}$ variability was comparable to patients with poor glycemic control. Our study supported that further targeting on $\mathrm{HbA} 1 \mathrm{c}$ stability after good glycemic control is crucial to reduce the risk of HF. In our clinical practice, some anti-diabetic agents having HF benefits and an effect to reduce $\mathrm{HbA1c}$ variability $[22,23]$ which may prioritize its clinical use in T2DM patients with HF.

Table 3. Association of mean and variability of $\mathrm{HbA} 1 \mathrm{c}$ with heart failure in the literature.

\begin{tabular}{|c|c|c|c|c|c|c|}
\hline Reference & $\begin{array}{c}\text { Year of } \\
\text { Publication }\end{array}$ & $\begin{array}{l}\text { Type of } \\
\text { Study }\end{array}$ & $\begin{array}{l}\text { Total Patients } \\
\text { (n) }\end{array}$ & $\begin{array}{c}\text { Follow-Up } \\
\text { Year }\end{array}$ & $\begin{array}{c}\text { Total Event } \\
(n)\end{array}$ & Associated Risk \\
\hline \multicolumn{7}{|c|}{ Association of mean $\mathrm{HbA} 1 \mathrm{c}$ with heart failure } \\
\hline Iribarren [8] & 2001 & Cohort & 48,858 & 2.2 years & 935 & $\begin{array}{c}\text { Each } 1 \% \text { increase in } \mathrm{HbA} 1 \mathrm{c} \\
\text { with an } 8 \% \text { increased risk of } \\
\mathrm{HF}(95 \% \mathrm{CI} 5-12) \text {. An } \mathrm{HbA} 1 \mathrm{c} \\
\geq 10 \% \text {, relative to } \mathrm{HbA} 1 \mathrm{c}<7 \% \text {, } \\
\text { with } 1.56 \text {-fold }(95 \% \mathrm{CI} \\
1.26-1.93) \text { risk of } \mathrm{HF}\end{array}$ \\
\hline $\begin{array}{c}\text { Pazin-Filho } \\
\text { [9] }\end{array}$ & 2008 & $\begin{array}{l}\text { Atherosclerosis } \\
\text { Risk in } \\
\text { Communities } \\
\text { (ARIC) study }\end{array}$ & 1827 & 9.9 years & 328 & $\begin{array}{c}\text { Each } 1 \% \text { higher } \mathrm{HbA} 1 \mathrm{c}, \mathrm{HR} \\
1.17(95 \% \text { CI } 1.11-1.25) \text { for the } \\
\text { non-CHD group and } 1.20(95 \% \\
\text { CI 1.04-1.40) for the CHD } \\
\text { group }\end{array}$ \\
\hline Lind [10] & 2012 & $\begin{array}{l}\text { Swedish } \\
\text { National } \\
\text { Diabetes } \\
\text { Register }\end{array}$ & 83,021 & 7.2 years & 10,969 & $\begin{array}{c}\text { Each 1\% higher HbA1c, HR } \\
1.12 \text { (95\% CI 1.10-1.14) for HF } \\
\text { hospitalization }\end{array}$ \\
\hline
\end{tabular}


Table 3. Cont.

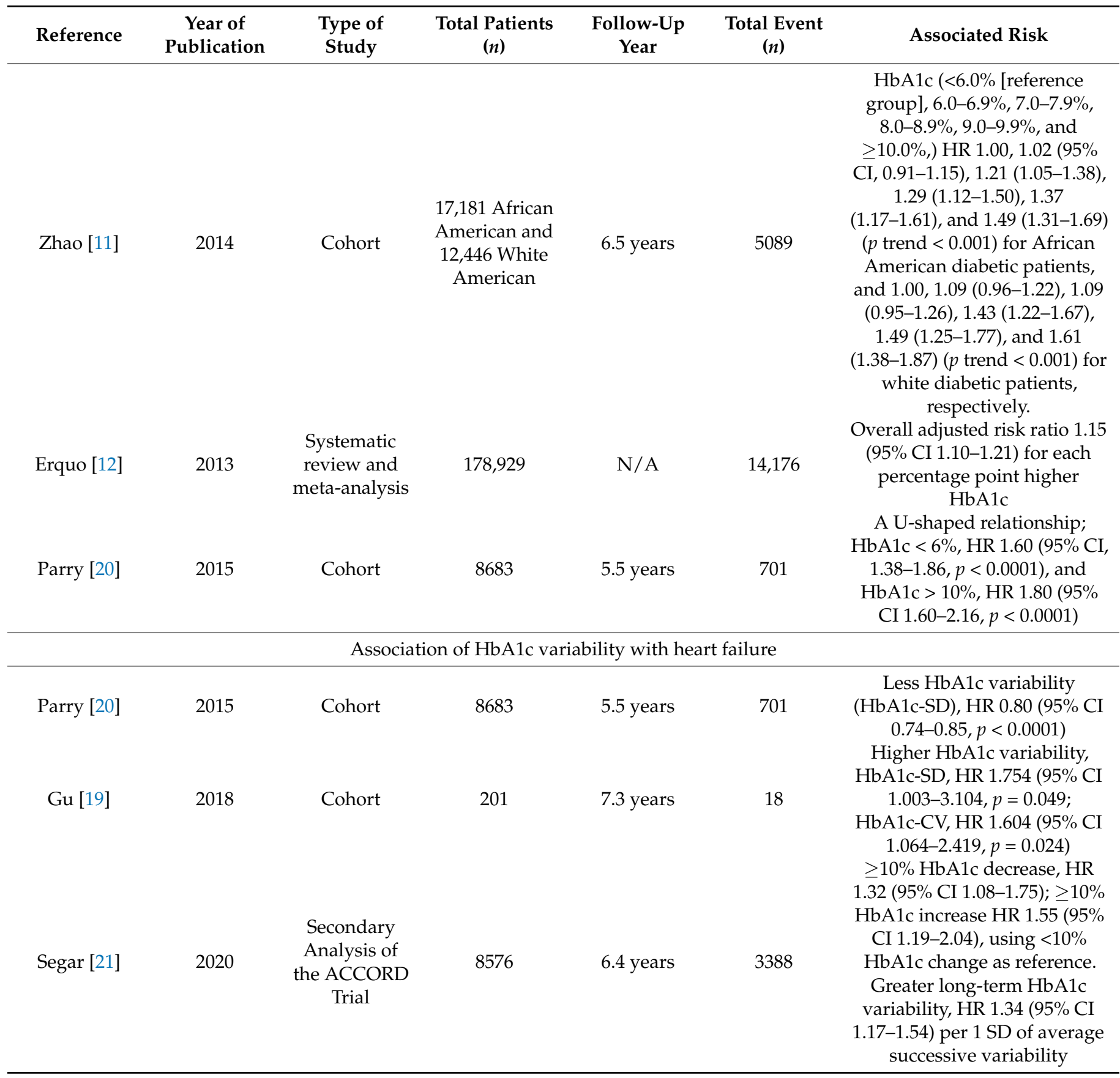

ACCORD, Action to Control Cardiovascular Risk in Diabetes; CI, confidence interval; HF, heart failure; HR, hazard ratio; SD, standard deviation.

An excess production of reactive oxygen species (ROS) has been reported to be an important pathophysiology to develop HF [24]. Several pieces of evidence revealed that ROS mediate mitochondrial damage, and activate several hypertrophy signal kinases and transcription factors to induce apoptosis [24]. It may also activate poly(ADP-ribose) polymerase-1 leading to the expression of a variety of inflammatory mediators which facilitate the progression of cardiac remodeling [24]. Furthermore, ROS is a stimulus for myocardial matrix metalloproteinases (MMPs) activation. Sustained myocardial MMP activation may lead to myocardium fibrosis [24]. Finally, ROS has a direct effect on myocardial contractile function by modifying excitation-contraction coupling proteins [24]. A previous study showed that acute $(24 \mathrm{~h})$ glucose fluctuations activate more oxidative stress than chronic hyperglycemia (by using one baseline $\mathrm{HbA1c}$ level) [25]. Another 
study also revealed that acute $(24 \mathrm{~h})$ glucose oscillations produce more oxidative stress than $24 \mathrm{~h}$ mean blood glucose level at $180 \mathrm{mg} / \mathrm{dL}$ [26]. However, these two studies were unable to explain our results because the glucose exposure period was rather short in comparison with our study. Moreover, the underlying mechanism(s) to explain why the effect of absolute $\mathrm{HbA1c}$ level on $\mathrm{HF}$ was greater than $\mathrm{HbA1c}$ variability remains unclear. The possible mechanism(s) needs further investigation in the future.

The strength of this study included a large sample size with long-term follow-up of real-world data. Nevertheless, our study had some limitations. First, the patients in this study were from a tertiary referral outpatient clinic. They are usually more complicated. Therefore, our findings may not be generalizable to all patients with diabetes. Second, most of our patients were on sulfonylureas and used less metformin and statins; such medication regimens are different from current managements. This difference should be considered before generalizing our results to patients with current medication patterns. Finally, as the inherent limitation of a database, we do not have detailed history, symptoms, and signs for the diagnosis of HF. We cannot categorize HF into HF with preserved ejection fraction and HF with reduced ejection fraction; echocardiography and laboratory data are also lacking to confirm the diagnosis [27].

\section{Conclusions}

In conclusion, our study shows that higher mean $\mathrm{HbA1c}$ was independently associated with increased risk of $\mathrm{HF}$ regardless of $\mathrm{HbA1c}$ variability. In patients with good glycemic control, less $\mathrm{HbA1c}$ variability was pivotal for the development of $\mathrm{HF}$.

Supplementary Materials: The following are available online at https:/ / www.mdpi.com/article/10 $.3390 /$ jcm10071401/s1, Figure S1: Flowchart of included patients, Table S1: ICD-9-CM and ICD-10CM codes, Table S2: Hazard ratios by categories of tertiles of HbA1c-SD or HbA1c-adjSD and cutoffs of $\mathrm{HbA1c}-M e a n$.

Author Contributions: Conceptualization, Y.-T.L., W.-L.H. and C.-C.C.; methodology, H.-P.W., M.P.C. and C.-C.C.; software, H.-P.W., M.-P.C. and C.-C.C.; validation, H.-P.W., M.-P.C. and C.-C.C.; formal analysis, H.-P.W., M.-P.C. and C.-C.C.; writing-original draft preparation, H.-P.W., M.P.C. and C.-C.C.; writing-review and editing, H.-P.W., M.-P.C. and C.-C.C.; visualization, C.-C.C.; supervision, C.-C.C. All authors have read and agreed to the published version of the manuscript.

Funding: This research was funded by China Medical University Hospital, grant number DMR-109-030.

Institutional Review Board Statement: This study was approved and granted a waiver of informed consent by the Ethical Review Board of China Medical University Hospital in Taiwan (CMUH107REC2-163). All methods were carried out in accordance with the Declaration of Helsinki.

Informed Consent Statement: The Ethical Review Board of China Medical University Hospital in Taiwan granted a waiver of informed consent because the research involves no more than minimal risk and It is not practicable to conduct the research without the waiver.

Data Availability Statement: The datasets generated during and/or analyzed during the current study are available from the corresponding author on reasonable request. Application to use the database of the Taiwan National Health Insurance must be a Taiwanese researcher.

Acknowledgments: We thank the China Medical University branch center of Taiwan Health and Welfare Data Science Center to organize the use of the database of Taiwan National Health Insurance. This study is supported by a grant from the China Medical University Hospital, Taiwan (DMR-109-030).

Conflicts of Interest: The authors declare no conflict of interest.

\section{References}

1. Shah, A.D.; Langenberg, C.; Rapsomaniki, E.; Denaxas, S.; Pujades-Rodriguez, M.; Gale, C.P.; Deanfield, J.; Smeeth, L.; Timmis, A.; Hemingway, H. Type 2 diabetes and incidence of cardiovascular diseases: A cohort study in 1.9 million people. Lancet Diabetes Endocrinol. 2015, 3, 105-113. [CrossRef] 
2. Carr, A.A.; Kowey, P.R.; Devereux, R.B.; Brenner, B.M.; Dahlöf, B.; Ibsen, H.; Lindholm, L.H.; Lyle, P.A.; Snapinn, S.M.; Zhang, Z.; et al. Hospitalizations for new heart failure among subjects with diabetes mellitus in the RENAAL and LIFE studies. Am. J. Cardiol. 2005, 96, 1530-1536. [CrossRef]

3. Zareini, B.; Blanche, P.; D’Souza, M.; Elmegaard Malik, M.; Nørgaard, C.H.; Selmer, C.; Gislason, G.; Kristensen, S.L.; Køber, L.; Torp-Pedersen, C.; et al. Type 2 diabetes mellitus and impact of heart failure on prognosis compared to other cardiovascular diseases: A nationwide study. Circ. Cardiovasc. Qual. Outcomes 2020, 13, e006260. [CrossRef] [PubMed]

4. McAllister, D.A.; Read, S.H.; Kerssens, J.; Livingstone, S.; McGurnaghan, S.; Jhund, P.; Petrie, J.; Sattar, N.; Fischbacher, C.; Kristensen, S.L.; et al. Incidence of hospitalization for heart failure and case-fatality among 3.25 million people with and without diabetes mellitus. Circulation 2018, 138, 2774-2786. [CrossRef] [PubMed]

5. Chen, H.F.; Ho, C.A.; Li, C.Y. Risk of heart failure in a population with type 2 diabetes versus a population without diabetes with and without coronary heart disease. Diabetes Obes. Metab. 2019, 21, 112-119. [CrossRef]

6. Kannel, W.B.; Hjortland, M.; Castelli, W.P. Role of diabetes in congestive heart failure: The Framingham study. Am. J. Cardiol. 1974, 34, 29-34. [CrossRef]

7. Klajda, M.D.; Scott, C.G.; Rodeheffer, R.J.; Chen, H.H. Diabetes mellitus is an independent predictor for the development of heart failure: A population study. Mayo Clin. Proc. 2020, 95, 124-133. [CrossRef]

8. Iribarren, C.; Karter, A.J.; Go, A.S.; Ferrara, A.; Liu, J.Y.; Sidney, S.; Selby, J.V. Glycemic control and heart failure among adult patients with diabetes. Circulation 2001, 103, 2668-2673. [CrossRef] [PubMed]

9. Pazin-Filho, A.; Kottgen, A.; Bertoni, A.G.; Russell, S.D.; Selvin, E.; Rosamond, W.D.; Coresh, J. HbA 1c as a risk factor for heart failure in persons with diabetes: The Atherosclerosis Risk in Communities (ARIC) study. Diabetologia 2008, 51, 2197-2204. [CrossRef] [PubMed]

10. Lind, M.; Olsson, M.; Rosengren, A.; Svensson, A.M.; Bounias, I.; Gudbjörnsdottir, S. The relationship between glycaemic control and heart failure in 83,021 patients with type 2 diabetes. Diabetologia 2012, 55, 2946-2953. [CrossRef]

11. Zhao, W.; Katzmarzyk, P.T.; Horswell, R.; Wang, Y.; Johnson, J.; Hu, G. HbA1c and heart failure risk among diabetic patients. J Clin. Endocrinol. Metab. 2014, 99, e263-e267. [CrossRef] [PubMed]

12. Erqou, S.; Lee, C.T.; Suffoletto, M.; Echouffo-Tcheugui, J.B.; de Boer, R.A.; van Melle, J.P.; Adler, A.I. Association between glycated haemoglobin and the risk of congestive heart failure in diabetes mellitus: Systematic review and meta-analysis. Eur. J. Heart Fail. 2013, 15, 185-193. [CrossRef]

13. Stratton, I.M.; Adler, A.I.; Neil, H.A.; Matthews, D.R.; Manley, S.E.; Cull, C.A.; Hadden, D.; Turner, R.C.; Holman, R.R. Association of glycaemia with macrovascular and microvascular complications of type 2 diabetes (UKPDS 35): Prospective observational study. BMJ 2000, 321, 405-412. [CrossRef]

14. Hirakawa, Y.; Arima, H.; Zoungas, S.; Ninomiya, T.; Cooper, M.; Hamet, P.; Mancia, G.; Poulter, N.; Harrap, S.; Woodward, M.; et al. Impact of visit-to-visit glycemic variability on the risks of macrovascular and microvascular events and all-cause mortality in type 2 diabetes: The ADVANCE trial. Diabetes Care. 2014, 37, 2359-2365. [CrossRef]

15. Luk, A.O.; Ma, R.C.; Lau, E.S.; Yang, X.; Lau, W.W.; Yu, L.W.; Chow, F.C.; Chan, J.C.; So, W.Y. Risk association of HbA1c variability with chronic kidney disease and cardiovascular disease in type 2 diabetes: Prospective analysis of the Hong Kong Diabetes Registry. Diabetes Metab. Res. Rev. 2013, 29, 384-390. [CrossRef] [PubMed]

16. Mo, Y.; Zhou, J.; Ma, X.; Zhu, W.; Zhang, L.; Li, J.; Lu, J.; Hu, C.; Bao, Y.; Jia, W. Haemoglobin A1c variability as an independent correlate of atherosclerosis and cardiovascular disease in Chinese type 2 diabetes. Diab. Vasc. Dis. Res. 2018, 15, 402-408. [CrossRef] [PubMed]

17. Tseng, J.Y.; Chen, H.H.; Huang, K.C.; Hsu, S.P.; Chen, C.C. Effect of mean HbA1c on the association of HbA1c variability and all-cause mortality in patients with type 2 diabetes. Diabetes Obes. Metab. 2020, 22, 680-687. [CrossRef] [PubMed]

18. Kilpatrick, E.S.; Rigby, A.S.; Atkin, S.L. A1C variability and the risk of microvascular complications in type 1 diabetes: Data from the Diabetes Control and Complications Trial. Diabetes Care 2008, 31, 2198-2202. [CrossRef]

19. Gu, J.; Fan, Y.Q.; Zhang, J.F.; Wang, C.Q. Association of hemoglobin A1c variability and the incidence of heart failure with preserved ejection fraction in patients with type 2 diabetes mellitus and arterial hypertension. Hellenic J. Cardiol. 2018, 59, 91-97. [CrossRef]

20. Parry, H.M.; Deshmukh, H.; Levin, D.; Van Zuydam, N.; Elder, D.H.; Morris, A.D.; Struthers, A.D.; Palmer, C.N.; Doney, A.S.; Lang, C.C. Both high and low HbA1c predict incident heart failure in type 2 diabetes mellitus. Circ. Heart Fail. 2015, 8, $236-242$. [CrossRef]

21. Segar, M.W.; Patel, K.V.; Vaduganathan, M.; Caughey, M.C.; Butler, J.; Fonarow, G.C.; Grodin, J.L.; McGuire, D.K.; Pandey, A. Association of long-term change and variability in glycemia with risk of incident heart failure among patients with type 2 diabetes: A secondary analysis of the ACCORD trial. Diabetes Care 2020, 43, 1920-1928. [CrossRef] [PubMed]

22. Ceriello, A.; Ofstad, A.P.; Zwiener, I.; Kaspers, S.; George, J.; Nicolucci, A. Empagliflozin reduced long-term HbA1c variability and cardiovascular death: Insights from the EMPA-REG OUTCOME trial. Cardiovasc. Diabetol. 2020, 19, 176-182. [CrossRef] [PubMed]

23. Kwak, S.H.; Hwang, Y.C.; Won, J.C.; Bae, J.C.; Kim, H.J.; Suh, S.; Lee, E.Y.; Lee, S.; Kim, S.Y.; Kim, J.H. Comparison of the effects of gemigliptin and dapagliflozin on glycaemic variability in type 2 diabetes: A randomized, open-label, active-controlled, 12-week study (STABLE II study). Diabetes Obes. Metab. 2020, 22, 173-181. [CrossRef] 
24. Tsutsui, H.; Kinugawa, S.; Matsushima, S. Oxidative stress and heart failure. Am. J. Physiol. Heart Circ. Physiol. 2011, 301, 2181-2190. [CrossRef] [PubMed]

25. Monnier, L.; Mas, E.; Ginet, C.; Michel, F.; Villon, L.; Cristol, J.P.; Colette, C. Activation of oxidative stress by acute glucose fluctuations compared with sustained chronic hyperglycemia in patients with type 2 diabetes. JAMA 2006, 295, $1681-1687$. [CrossRef]

26. Ceriello, A.; Esposito, K.; Piconi, L.; Ihnat, M.A.; Thorpe, J.E.; Testa, R.; Boemi, M.; Giugliano, D. Oscillating glucose is more deleterious to endothelial function and oxidative stress than mean glucose in normal and type 2 diabetic patients. Diabetes 2008, 57, 1349-1354. [CrossRef] [PubMed]

27. Ponikowski, P.; Voors, A.A.; Anker, S.D.; Bueno, H.; Cleland, J.G.; Coats, A.J.; Falk, V.; González-Juanatey, J.R.; Harjola, V.P.; Jankowska, E.A.; et al. 2016 ESC Guidelines for the diagnosis and treatment of acute and chronic heart failure: The Task Force for the diagnosis and treatment of acute and chronic heart failure of the European Society of Cardiology (ESC). Developed with the special contribution of the Heart Failure Association (HFA) of the ESC. Eur. J. Heart Fail. 2016, 18, 891-975. 